\title{
Mechanised installation of rolled high tensile strength steel wire mesh for ground support: Canadian trial observations
}

\author{
C Pritchard Pritchard Mining Technologies Inc., Canada \\ E Rorem Geobrugg North America, LLC, USA \\ D Landry Vale Canada Ltd., Canada \\ B Whitmell Vale Canada Ltd., Canada
}

\begin{abstract}
Rolled high tensile strength steel wire mesh for above-ground surface retention of landslides, over-steepened slopes, pit slopes and roadway exposures has been used globally for decades with high success and has become a standard of practice. Underground mining applications of the Geobrugg rolled mesh are now being used internationally in major block caving and other mining operations with good success and with well-documented performance tests. (Bucher et al. 2013) Furthermore, several other mine site-specific evaluations of cycle-time have documented efficiency improvements (Tonkin 2011).

Canadian mines are seeing the need for improved surface support as mining depth increases. A working site evaluation of the rolled mesh is underway at an underground mine in Sudbury, Ontario. Here, a lighter version rolled mesh is being mechanically installed with an Epiroc Boltec boom bolter fitted with an unrolling device on the screen-handling boom.

The first phase of this evaluation is intended to provide proof of concept specific to the mine. Key performance indicators are operator hazard exposure, cycle times and other efficiency measures, such as drilling time requirements, consumption of rockbolts, mesh, shotcrete and corrosion resistance, post-blast rehab requirements other effects on operations have been documented. The MINAX ${ }^{\circledR}$ 80-3 mesh used thus far is a lighter version intended for gravity conditions. A heavier version MINAX ${ }^{\circledR} 80-4$ mesh is ideal for highstress and bursting ground conditions and will be tried later after this initial proof of concept. An additional consideration was to be able to prove that mild steel galvanised welded wire mesh (GWWM), or sheet mesh could still be installed on the blasted face with the same machine setup as for the rolled mesh.

All indications thus far are that the mesh and mesh installation represent a viable alternative to current surface support processes, which can improve both safety and efficiency of operations at the minimum while providing the opportunity for improved surface support performance in high-stress ground conditions. The initial results and observations of this first Canadian evaluation of the high tensile rolled mesh will be reported when complete.
\end{abstract}

Keywords: wire roll mesh, dynamic surface support, mechanised roll mesh installer

\section{$1 \quad$ Introduction}

For 10+ years, high strength tensile steel wire roll mesh has been successfully applied and installed in many world-class mining operations in Chile, Spain, Australia, South Africa, Mexico, Turkey and Russia. The success of these applications has grown to include an evaluation at Vale's Coleman mine in Sudbury which hosts four massive copper and nickel sulphide orebodies. The application trials of the Geobrugg roll mesh within their variable mine development and ground conditions have met the challenges with good success. The installation pairs the use of the Epiroc Boltec - EC and the Geobrugg provided MESHA ${ }^{\circledR}$ device to facilitate the applications of the rolled mesh. (Figure 1). The rolled mesh from Geobrugg is a chainlink mesh construction, using high tensile strength steel wire. The key goal of this approach is to reduce operator 
exposure to the high risk zone, with demonstration of efficiency improvement as a secondary but important consideration. Within the evaluation period, the installation has proven where the mesh application works best and where more work is required. The installations within the Coleman orebody where shotcrete is applied over the lighter MINAX $^{\circledR}$ 80-3 $(80 \mathrm{~mm}$ diamond-shaped opening and $3 \mathrm{~mm}$ high tensile wire) has been challenging and has resulted in re-bolting the shoulders and parts of the back where loose mesh areas can be a concern. Where no shotcrete is applied the 80-3 mesh works as planned. The lighter gauge 80-3 mesh has encountered infrequent but similar conditions in some operations. Currently the MESHA ${ }^{\oplus}$ device has the capacity to bolt a $5 \times 5 \times 4 \mathrm{~m}$ advance with one roll (two mesh pieces per roll, and thus two passes of the mesh per roll) of the 80-3 mesh in one round set up.

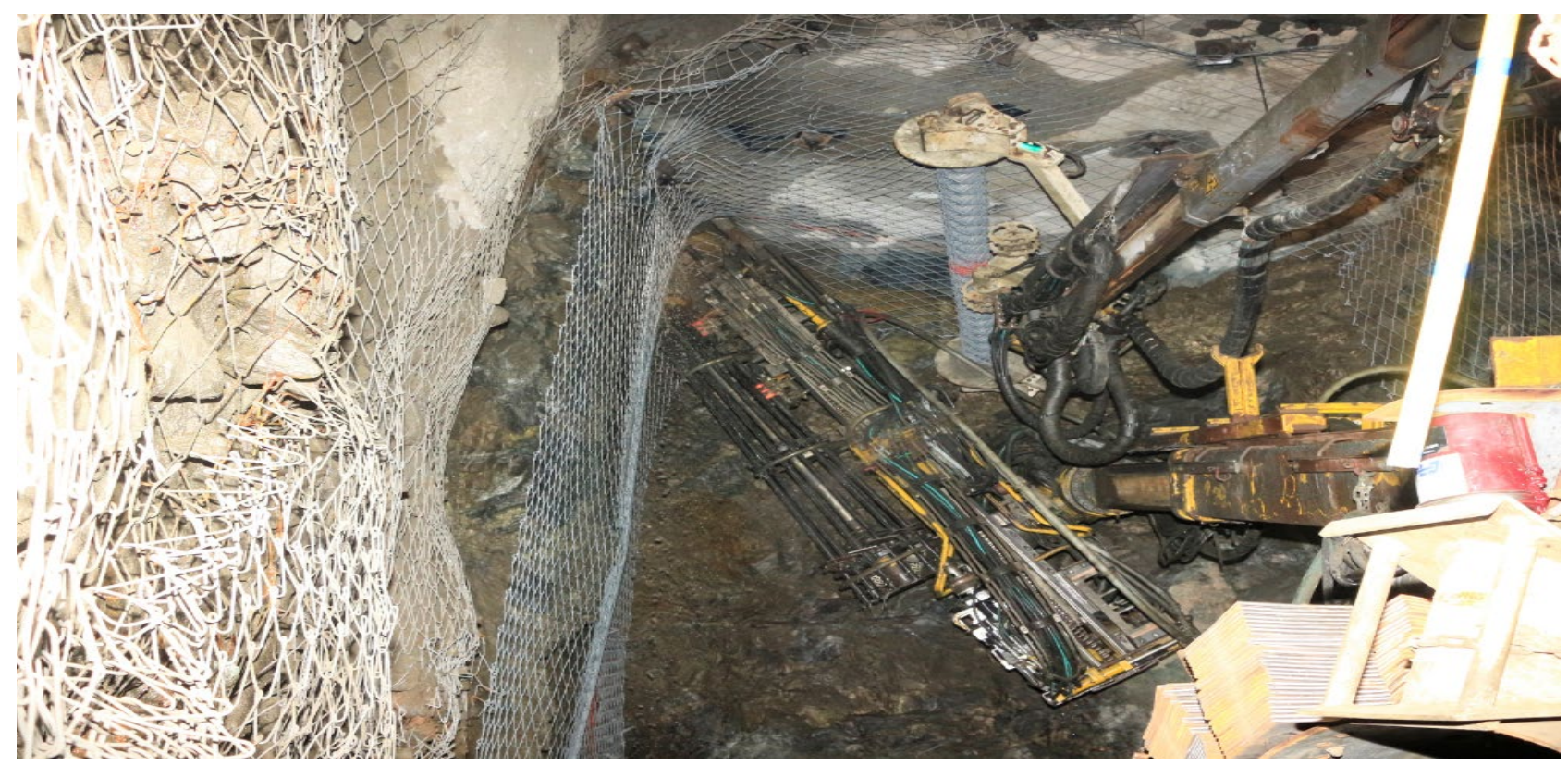

Figure 1 Application of rolled mesh with the unrolling device in an under-hand cut-and-fill heading (Photo courtesy Vale)

The MINAX ${ }^{\circledR} 80-4$ mesh (4 mm wire) is a heavier and stiffer material with more resistance. Testing of the $80-4$ mesh where shotcrete is applied needs to be evaluated at Coleman as part of the evaluation (Figure 2).

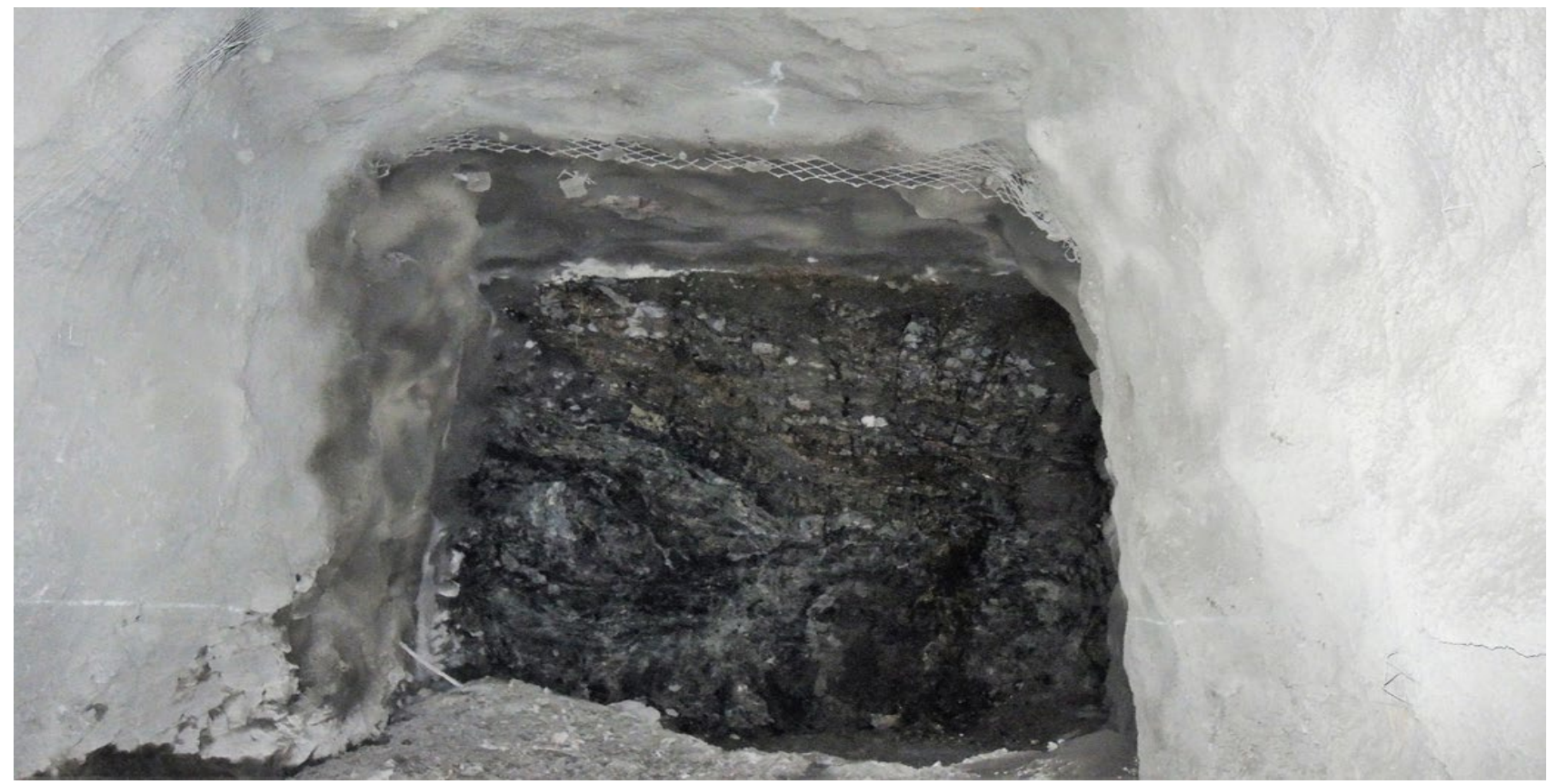

Figure 2 Rolled mesh and shotcrete application in an undercut and fill drift (Photo courtesy Vale) 
The potential is to expand its use in deep and high-stress development with the hope of limiting the use of shotcrete, except for in the most dynamic of condition or applications. The logistic considerations of these savings are a key point for deep mining. The capacity of the 80-4 mesh is significantly more than the 80-3 mesh, but has some consequences to consider. The mesh is heavier and thus only one piece of mesh can be accommodated per roll, thereby requiring two rolls to be handled per round. The unrolling device easily handles both products, but the current Coleman Boltec/MESHA configuration device does not have the extra capacity and hydraulic power to complete the application of a two piece roll. Future considerations for deep mining may include a more robust screen-handling arm and hydraulic capacity to eliminate the need to reload the 80-4 mesh.

\section{In-cycle considerations with rolled mesh}

Cost savings are part of the justification for using the roll meshes. The application of continuous sheets of mesh significantly reduces the need for redundant bolts on the screen seams which is common ground support application. Preliminary audit reports suggest a potential decrease of $15-20 \%$ reduction in bolts used, due in part to fewer mesh seams to bolt. The roll mesh overlap remaining creates radial seams from floor to floor on each round.

The unrolling device can be removed quickly if the bolter needs to revert back to the installation of mild steel sheet mesh using the traditional sheet mesh manipulator device. Or, the device is fitted with screen mesh handling grippers to allow bolting the face with sheet screen with the same bolter set up per round as for the rolled mesh.

Other favourable considerations is transportation to deep sections of the underground mines and to remote sites where this is a considerable operational cost.

Due to the strength and durability of the high strength tensile steel wire mesh, rehabilitation cycle benefits when using the roll mesh include reductions in the use of sheet screen. Multiple rehabilitation cycles can be reduced even as conditions become more challenging and dynamic. Equipment damage to main mine accesses can be significant and result in costly production delays. Applying the mesh to the mine's main access areas can provide greater resistance to limit this. If rehabilitation is required to the low walls the roll mesh can be applied lengthwise followed by bolting with fewer screen overlapping and lower bolting times. Shotcreting over these sections will further reduce the rehabilitation frequency.

Corrosion resistance offered by the high strength tensile wire is significant. During the wire manufacturing, the high strength steel wire rods are galvanised with a zinc/aluminium alloy prior to drawing the wire through the forging dies to obtain the desired wire diameter that result in a very smooth surface. This process has been tested and due to the chemistry has proven superior to the zinc-only galvanising process common for standard mild steel GWWM. Advance testing at the Geobrugg lab in Switzerland and field verification has been completed for corrosion resistance in surface pit applications and underground applications. In underground mines, this corrosion resistance will reduce both rehabilitation cycle frequency and the need to re-bolt areas intersecting massive sulphide contacts. Fully encapsulated bolts are recommended for all of these applications, to reduce the bolts exposure to long-term corrosion and ensure they will last at least as long as the mesh. This is a possible consideration for sill mat constructions where the mat is subjected to years of corrosive degradation.

Successful retention of deforming and bursting ground has been observed in many operations and trial applications at various sites. Observations suggest that associated deformations have occurred within the support elements, without unzipping or failing the mesh's continuous weave. Minimal rehabilitation, if required, is generally for the application of a few extra 'safety bolts' to push the mesh back into place. In all observed locations, capacity of the mesh has not been exceeded. 


\section{Recognised safety improvements}

The mining industry must manage risks well to keep workers safe. Future mining will involve production generally in deeper higher stress environments, some of these processes will require further adaptations to minimise risk and exposures. The application of the roll mesh in mines has potential to minimise the ergonomic risks of manually lifting and handling sheet mesh while further reduced exposures. As ground support is one of the biggest time elements in the mining cycle, proactively taking steps to utilise better equipment, adapt new processes and utilise new support systems can lead to reduced worker exposure. A reduction in musculoskeletal injuries from lifting and handling mesh panels is anticipated. In addition, injuries from handling mesh, repetitive climbing onto and off the bolter are the expected outcome.

\section{$4 \quad$ Special note}

Any high strength tensile mesh application on the development face in ore headings should be avoided. When used in a production setting, the ore handling system needs to be fitted with a scalping system and a high powered magnet for removal of the high strength tensile mesh, as this mesh does not break apart during mucking like mild steel versions of sheet mesh (Figure 3 ).

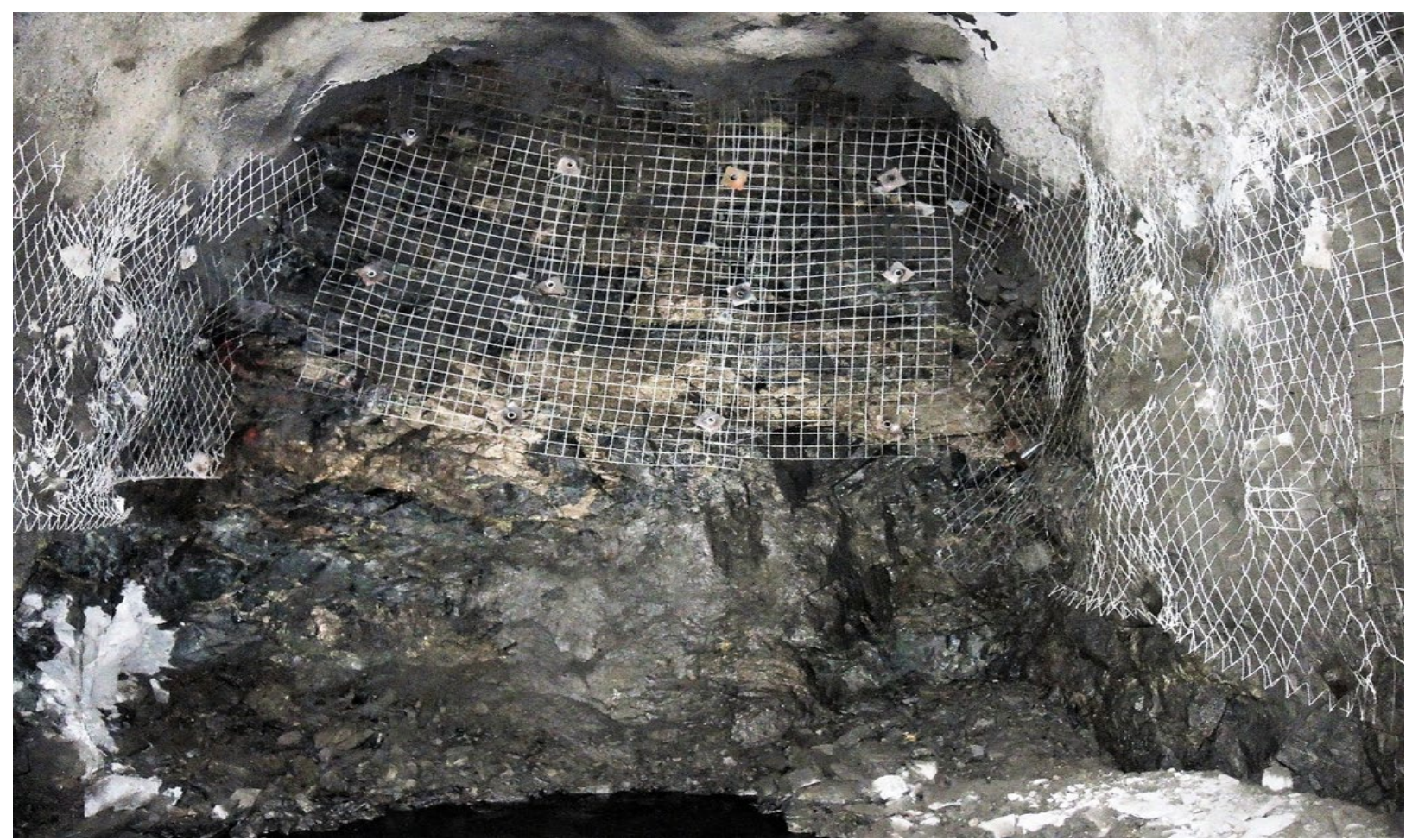

Figure 3 Showing GWWM face screen and rolled mesh application on back and walls (photo courtesy Vale)

Equipment and blast damage has been witnessed on occasion with the lighter 80-3 mesh requires patching with sheet screen or small pieces of rolled mesh using special snap on clips, or replacing sections to bring the support back to mine standard. The applications of the heavier mesh to date have not been challenged by these conditions.

Shotcrete applications at Coleman mine use an underground batch plant to blend dry bagged shotcrete with water to achieve a wet mix shotcrete product. The trial at Coleman occurred in the under cut-and-fill headings and the ground support system include bolting and screening the development round, followed by a layer of shotcrete over the mesh. Experience indicated that the 80-3 caused a loss of shotcrete adhesion and excessive rebound to occur (Figure 4). There are two primary reasons why this occurred; product application issues with the shotcrete process (possibly related to applied angle, nozzle offset, or 
the age of the shotcrete) and lack of stiffness with the rolled mesh that causes movement, when shotcrete was applied (Figure 5). This occurrence was frequently seen in the shoulders and transition to the back where mesh bridging tends to occur and thus reduces less intimate contact of the mesh with the rock surface.

The winter of 2018-2019 in Northern Ontario has been unusually cold, adding to the issues with getting the dry bagged material out of cold storage and up to ambient mine temperature before application. The process of mixing the dry bagged to wet material is well established and the equipment used for this purpose is good and well maintained. The shotcrete operators are well trained with applications and the product supplier does frequent $Q A / Q C$ and evaluative testing of the application and product.

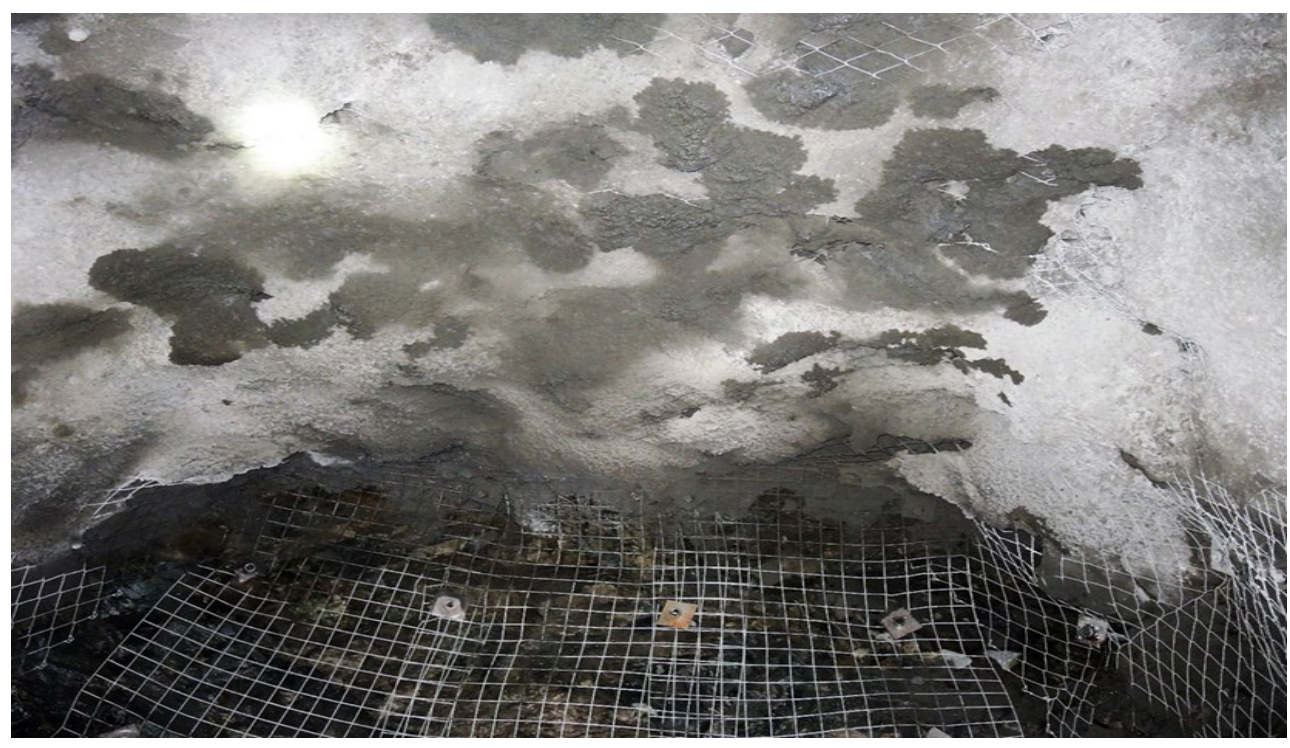

Figure 4 Showing poor shotcrete application results on the 80-3 mesh (photo courtesy Vale)

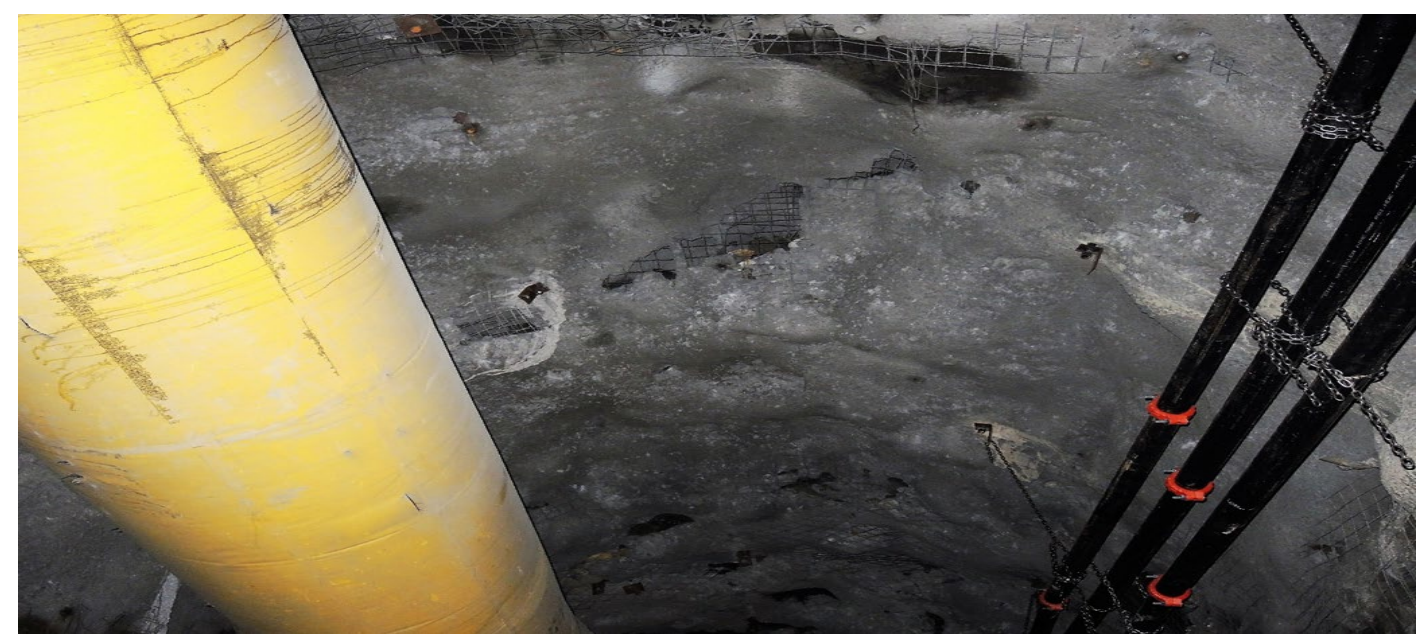

Figure 5 Showing shotcrete dropout and voids on the GWWM and rolled mesh (photo courtesy Vale)

The mesh being a stiffer and more robust mesh is more receptive to shotcrete applications in other mines. The use of this mesh at Coleman mine has only been applied where shotcrete is not required. Moving forward, this will be evaluated under similar conditions to the mesh for comparison. The benefits of this in the development cycle include cost saving while ensuring a quality support installation. (Louchnikov et al. 2014). 


\section{$5 \quad$ Future application with heavier rolled 80-4 Mesh}

The mesh will be trialled at Coleman mine to gather more information to evaluate potential applications and performance in a normal (low to moderate stress) environment. The goal is to trial the heavier mesh in high-stress areas where dynamic rock loading conditions are expected. Coleman planned production includes development to a new orebody with sublevel and stope accesses in elevated stress conditions. This would be seen as a good evaluative test for the mine plan with use of the 80-4 mesh. The support would be subjected to higher amounts of stress deformation and corrosion while testing a reduction in support installation and potential cost savings.

Positive, but limited operator feedback on this application process during the trials has been difficult to routinely document. A serious attempt to gather operational data was started in October 2018, and offers a limited look at the applications. The limited data offers a valid insight into the time and application benefits of the 80-3 mesh over a total of 29 bolted rounds. Throughout the 6 month evaluation period, the use and applications of the MINAX ${ }^{\circledR}$ products have been challenging at no fault of the mine operations. A single BOLTEC - EC boom bolter was fitted with the MESHA ${ }^{\circledR}$ device. Other demands on the bolter have been high so the roll mesh application has been limited.

\section{Conclusions and path forward}

The trial at Coleman mine was successful in the fact that it tested a step change in possible ground support installation technology. The goal was to show the rolled mesh could be installed while reducing operator exposure. The trial identified that the process needs further work to gather data for a more quantitative analyses to assess its suitability with shotcrete and further testing and in high-stress conditions.

\section{Acknowledgement}

The authors would like to thank Vale Canada Ltd., for the opportunity to submit this paper and for the ongoing support of this project. The information gathered to date has been a positive step towards safer mining at depth using advanced surface support techniques.

\section{References}

Bucher, R, Cala, M, Zimmermann, A, Balg, C \& Roth, A 2013, 'Large scale field tests of high-tensile steel wire mesh in combination with dynamic rockbolts subjected to rockburst loading', in Y Potvin \& B Brady (eds), Proceedings of the Seventh International Symposium on Ground Support in Mining and Underground Construction, Australian Centre for Geomechanics, Perth, pp. 221-232.

Louchnikov, V, Sandy, MP, Watson, O, Orunesu, M \& Eremenko, V 2014, 'An overview of surface rock support for deformable ground conditions', Proceedings of the 12th AusIMM Underground Operators' Conference, The Australasian Institute of Mining and Metallurgy, Melbourne.

Tonkin, CJ 2011, Time and Motion Study of Sheeted Wire Meshing and Rolled Wire Mesh Systems. Goldfields: South Deep, University of Pretoria, Pretoria. 